\title{
Highly Antibacterial Activity Against Methicillin- resistant Staphylococcus aureus of Silver Nanoparticles Synthesized by Citrus maxima Peel Extract
}

\section{Thu Ha Bui}

Ho Chi Minh City University of Food Industry

Ngoc Dai Nghia Tran

Ho Chi Minh City University of Food Industry

Phung Anh Nguyen

Institute of Chemical Technology

Nhat Linh Duong

Ho Chi Minh City Open University

Van Minh Nguyen

Ho Chi Minh City Open University

Dinh Hong Nguyet Nguyen

Ho Chi Minh City Open University

Phuong Thao Nguyen

Ho Chi Minh City Open University

\section{Trung Dang-Bao}

Ho Chi Minh City University of Technology (HCMUT)

\section{Hong Phuong Phan}

Ho Chi Minh City University of Technology (HCMUT)

Nguyen Tri ( $\nabla$ ntri@ict.vast.vn )

Vietnam Academy of Science and Technology https://orcid.org/0000-0001-9486-5096

\section{Communications}

Keywords: Sunlight irradiation, silver nanoparticles, antibacterial, Citrus maxima peel

Posted Date: February 1st, 2021

DOl: https://doi.org/10.21203/rs.3.rs-160930/v1

License: (9) This work is licensed under a Creative Commons Attribution 4.0 International License. Read Full License 
Page 2/9 


\section{Abstract}

A cost-effective and green technique was performed for the synthesis of silver nanoparticles (AgNPs) from a plant resource using Citrus maxima peel (CMP) extract as a reducing agent. The formation of AgNPs was confirmed by UV-Vis Spectroscopy at the wavelength range of 400-500 $\mathrm{nm}$. The optimized conditions for the AgNPs synthesis using CMP extract as a reducing agent were determined. At these conditions, the X-ray diffraction (XRD) and the high-resolution transmission electron microscopy (HRTEM) results revealed the face-centered cubic structure of AgNPs had a highly crystalline with the particle size in a range of 10-20 nm. The Fourier transform infrared spectroscopy (FT-IR) demonstrated the presence of flavonoid, terpenoid, phenolic, and glycosides in phytochemical compositions of CMP extract which can act as the reducing agents for AgNPs formation. The antibacterial effect of the AgNPs was evaluated against Methicillin-resistant Staphylococcus aureus (MRSA) by implementing the minimum inhibitory concentration (MIC), minimum batericidal concentration (MBC), and the zone of inhibition tests. The AgNPs exhibited effective antibacterial activity against bacteria with an average diameter of inhibition zones of $11.7 \mathrm{~mm}$, the MIC of $8.27 \mu \mathrm{g} / \mathrm{mL}$, and the $\mathrm{MBC}$ of the $16.54 \mu \mathrm{g} / \mathrm{mL}$.

\section{Main Text}

Improper use of antibiotics promotes the growth of resistant bacteria. The prevalence of multidrugresistant infections has become a severe challenge in clinical practice. Bacteria such as $S$. aureus, $B$. cereus, $P$. aeruginosa, E. coli, etc. are becoming increasingly difficult to treat with conventional antibiotics [1]. Resistance can be transmitted between bacteria via plasmids. Unfortunately, resistant bacteria emerged shortly after the clinical use of new synthetic, synthetic antibiotics. Bacteria possess several universal mechanisms to fight different types of antibiotics. These mechanisms include producing antibiotic-specific degradation enzymes, altering membrane permeability, mutating/modifying efficient sites, and adjusting the translation system. Therefore, the urgent need is to develop biocides with alternative mechanisms. Silver nanoparticles (AgNPs) are useful in inhibiting drug-resistant bacteria [2,3]. It seems that the bacteria have a low resistance to AgNPs, supporting their use as a suitable biocide. An earlier study showed that AgNPs penetrated bacterial cells. The results showed that AgNPs could interact directly with cellular macromolecules. However, the bactericidal mechanism of AgNPs is not precise, with some controversial theories as follows. The first mechanism [4]: Oxidized AgNPs, releases free silver ions from the nanoparticle surface to be toxic to bacteria. However, characters containing fixed AgNPs exhibited better antimicrobial performance than silver ion coated surfaces, suggesting that AgNPs and $\mathrm{Ag}^{+}$have different bactericidal pathways. The second mechanism [5]: AgNPs break down the membrane/cell wall and thus inhibit aerobic respiration, damage deoxyribonucleic acid (DNA), disturb biosynthesis, and protein folding. The last mechanism [6]: Reactive oxygen species (ROS) generated by the AgNPs stimulate the light and then kill the bacteria. However, some studies find that AgNPs are in vitro antioxidants. In recent years, the exploitation of green technology to synthesize AgNPs has gained remarkable achievements. Various claims show that the AgNPs biosynthesis process focuses on a number of plant sources, in which the extraction of plant parts such as leaves [2,7], root [2], seed [8], stem 
and flower [9], and fruit [10] have been used effectively. Consequently, the synthesis of the AgNPs using plant extracts offers advancements over other methods with more effective applications, especially in antibacterial activities. In addition, the formation of AgNPs on supports, typically $\mathrm{SiO}_{2}$, with the aim of enhancing dispersion also provides high antibacterial performance [11].

Citrus maxima as a popular fruit is widely grown in Southeast Asia, especially in Vietnam. In many countries, in huge quantities, a Citrus maxima peel has always been considered a biomass waste. It has been reported that some phenolic acids, coumarin flavonoids, rutin, and terpenoids are abundant in the peel extract of Citrus maxima [12,13]. These compounds are considered natural antioxidants. Besides, they can also be used as an effective reducing agent to produce nanosilver. Therefore, AgNPs obtained from this process are more biocompatible and suitable for biomedical and industrial applications. This study conducted a synthesis of AgNPs at room temperature under sunlight irradiation, based on reducing $\mathrm{AgNO}_{3}$ solution using Citrus maxima peel extract (collected from Ben Tre province, Vietnam).

Furthermore, we studied their antimicrobial properties against Methicillin-resistant Staphylococcus aureus with the standardized inoculum of bacteria of $1.5^{\prime} 10^{7} \mathrm{CFU} \cdot \mathrm{mL}^{-1}$. Fabrication, characterization, and antibacterial activity testing of AgNPs using CMP extract are illustrated in Fig. 1 (more detailed, in Supplementary Information).

AgNPs formation was shown at room temperature under the irradiation of sunlight. The surface plasmon band of AgNPs demonstrated it observed in the wavelength region of 400-450 nm (Figure S1a). The intensity of this absorption increases as the concentration of $\mathrm{AgNO}_{3}$ rises from 0.75 to $1.25 \mathrm{mM}$. It shows an increase in the concentration of AgNPs, along with an increase in the concentration of $\mathrm{AgNO}_{3}$. However, AgNPs formation decreased at higher $\mathrm{AgNO}_{3}$ concentrations $(1.5 \mathrm{mM})$. Agglutination of small particles leading to a decrease in the concentration of AgNPs (lower absorption intensity) took place in this case. With the ratio of $\mathrm{AgNO}_{3} / \mathrm{CMP}$ extract of 19/1, the formation of AgNPs was almost negligible (Figure S1b). Increase the ratio of $\mathrm{AgNO}_{3} / \mathrm{CMP}$ extracts up to 16/4; the formation rate of AgNPs increases significantly. It is explained that the high concentration of biological molecules in the CMP extract has effectively reduced $\mathrm{Ag}^{+}$ions to $\mathrm{Ag}^{\circ}[14]$. AgNPs formation rate almost unchanged when increasing the ratio of $\mathrm{AgNO}_{3} / \mathrm{CMP}$ extract up to 15/5. Besides, it also has a red-shift of the absorption band, leading to an increase in the size of AgNPs. The effect of reaction time on the formation of AgNPs was also investigated. The AgNPs formation was observed at 120 minutes (Figure S1c). AgNPs formation intensity increased and maintained after 330 minutes. From the obtained results, the optimized conditions for the synthesis of AgNPs using CMP extract as a reducing agent were determined involving the presence of the light illumination, the volume ratio of $\mathrm{AgNO}_{3}$ solution/CMP extract of $18 / 2$, the $\mathrm{AgNO}_{3}$ concentration of $1.25 \mathrm{mM}$ and the reaction time of 330 minutes.

X-ray diffraction analysis (XRD) of AgNPs synthesized at the optimized conditions (Fig.S3) showed Several Bragg reflections with $2 \theta$ of $38.5,46.7,64.5$, and $77.3^{\circ}$ recorded corresponding to (111), (200), (220) and (311) lattice planes, characterizing of the face-centered cubic structure of AgNPs (JCPDS card No. 89-3722). A few intense with unassigned peaks in AgNPs structure's vicinage at $2 \theta=28.2,32.5,55.5$, 
and $56.9^{\circ}$ exhibited bio-organic phase crystals [24] in the CMP extract, which was useful for the reduction of $\mathrm{Ag}^{+}$ions. The average crystal size of AgNPs was estimated as $10.4 \mathrm{~nm}$ following the Debye-Scherrer equation.

FTIR spectra of CMP and AgNPs are recorded to find possible functional groups responsible for AgNPs biosynthesis (Fig.S4). The results showed that the biological molecules of CMP stick to the surface of the AgNPs solution. The peak at $3415 \mathrm{~cm}^{-1}$ can be attributed to the $\mathrm{O}-\mathrm{H}$ elongation oscillation of phenol groups on flavonoid rings [15], Absorption bands at 2930 and $1620 \mathrm{~cm}^{-1}$ are estimated to be due to prolonged fluctuation of $\mathrm{C}-\mathrm{H}$ and $\mathrm{C}=\mathrm{C}$, [15], respectively. The peak at $1375 \mathrm{~cm}^{-1}$ is assumed to be due to bending vibrations in the plane of $\delta(O-H)$. The peak at $1745 \mathrm{~cm}^{-1}$ could be a sign of the $\mathrm{C}=0$ group. Furthermore, the peaks at 1055 and $620 \mathrm{~cm}^{-1}$ can be attributed to the oscillation of $\mathrm{v}(\mathrm{C}-\mathrm{O})$ and $\delta(\mathrm{C}-\mathrm{H})$, respectively. It reported that flavonoids such as naringenin, hesperidin, and naringin are the main compounds found in CMP extract [12], which reduces $\mathrm{Ag}^{+}$and adsorption on the AgNPs surface to enhance their stability. Besides, other bioactive compounds such as phenolic acids, limonoids, coumarin, quercetin, rutin, and carotenoids also play an essential role in preparing AgNPs. In comparison with the pure CMP extract, insignificant differences of absorption bands with weaker signals were observed in AgNPs solution, attributed to a decrease of the biomolecules' concentration (involving the reduction of $\mathrm{Ag}^{+}$ions to $\left.\mathrm{Ag}^{0}[16]\right)$.

The HRTEM analysis showed the nanoparticles were spherical in shapes with a diameter range of 10-20 $\mathrm{nm}$ (Fig.S5). The HRTEM image demonstrated that the AgNPs had three planes of structured AgNPs, including the (111) and (200) planes with the d-spacings of 0.27 and $0.24 \mathrm{~nm}$, respectively. The EDS spectrum of AgNPs delivers high intense major peaks of elemental Ag with an atomic percentage of $70.8 \%$, which was typical for the absorption of metallic silver because of surface plasmon resonance (Fig. S6). The appearance of the weaker signals of O (11.2 wt.\%), C (15.4 wt.\%), and Cl (1.6 wt.\%) may be owing to the presence of bio-molecules that are bound to the surface of AgNPs. Besides, the carbon composition also is existed by the carbon tape covered the sample. The zeta potential in the double electrical layer surrounding AgNPs is $-17.7 \mathrm{mV}$ (Figure S7a). The result confirmed that the AgNPs possess high stability in the aqueous solution. The size distribution showed that AgNPs with a diameter of $12.2 \mathrm{~nm}$ had the highest appearance (Fig. S7b). This result is completely consistent with XRD and HRTEM analysis. The use of CMP extract as reducing and stabilizing agents permitted to obtain the spherical nanoparticles had small and uniform size at room temperature with sunlight irradiation assistance (Table 1).

Table 1. Synthesis of AgNPs using the leaf extract of different plants. 


\begin{tabular}{|lllll|}
\hline Plants & Plant's part & Shapes & Size (nm) & References \\
\hline Alternanthera dentate & Leaf & Spherical & $50-100$ & {$[17]$} \\
\hline Tea extract & Leaf & Spherical & $20-90$ & {$[18]$} \\
\hline Pistacia atlantica & Seed & Spherical & $10-50$ & {$[19]$} \\
\hline Acalypha indica & Leaf & Spherical & $20-30$ & {$[20]$} \\
\hline Citrus sinensis & Peel & Spherical & $10-35$ & {$[21]$} \\
\hline Vitis vinifera & Fruit & Spherical & $30-40$ & {$[22]$} \\
\hline Eclipta prostrate & Leaf & Triangles, pentagons, hexagons & $35-60$ & {$[23]$} \\
\hline Centella asiatica & Leaf & Spherical & $30-50$ & {$[24]$} \\
\hline Carica papaya & Leaf & Spherical & $25-50$ & {$[25]$} \\
\hline Nelumbo nucifera & Leaf & Spherical, triangular & $25-80$ & {$[26]$} \\
\hline Citrus maxima & Peel & Spherical & $10-20$ & This work \\
\hline
\end{tabular}

Fig.S8 showed the inhibition zone of the synthesized AgNPs sample against Methicillin-resistant Staphylococcus aureus (MRSA) bacteria. The average inhibition zone diameter was $11.7 \mathrm{~nm}$. The antibacterial activities of the obtained AgNPs were further determined by their corresponding minimum inhibitory concentration (MIC) and minimum batericidal concentration (MBC) shown in the Fig.S9. For MIC analysis, it was observed that the exponential phase of bacteria delayed in the presence of AgNPs and this phenomenon was more obvious with the increase of AgNPs concentration (Fig.S9a). The AgNPs synthesized at the optimized condition could delay the exponential phase of bacteria. The AgNPs could completely inhibit the MRSA bacteria at MIC of $8.27 \mu \mathrm{g} / \mathrm{mL}(\mathrm{N} / 16)$. For MBC analysis, the MBC value was found to be $16.54 \mu \mathrm{g} / \mathrm{mL}(\mathrm{N} / 8)$.

In conclusion, a cost-effective, fast, eco-friendly, and convenient green route for synthesizing AgNPs using CMP extract as a reducing agent at ambient temperature was proposed. The AgNPs synthesized at the optimized conditions were formed as highly crystallized spherical particles with a size range of 10-20 nm. The obtained AgNPs showed efficient antibacterial activity against Methicillin-resistant Staphylococcus aureus. Hence, the use of a green method for synthesizing AgNPs in this work may suggest using such nanoparticles in the inhibition of future antibiotic-resistant bacteria.

\section{Declarations}

Funding: Not applicable.

Competing Interests: The authors declare that they have no conflict of interest. 
1. Uddin, A. R., Siddique, M. A. B., Rahman, F., Ullah, A. A., Khan, R. (2020) Cocos nucifera Leaf Extract Mediated Green Synthesis of Silver Nanoparticles for Enhanced Antibacterial Activity. Journal of Inorganic and Organometallic Polymers and Materials, 1-12.

2. Behravan, M., Panahi, A. H., Naghizadeh, A., Ziaee, M., Mahdavi, R., Mirzapour, A. (2019) Facile green synthesis of silver nanoparticles using Berberis vulgaris leaf and root aqueous extract and its antibacterial activity. International Journal of Biological Macromolecules 124, 148-154.

3. Zarei, Z., Razmjoue, D., Karimi, J. Green Synthesis of Silver Nanoparticles from Caralluma tuberculata Extract and its Antibacterial Activity.

4. Lok, C.-N., Ho, C.-M., Chen, R., He, Q.-Y., Yu, W.-Y., Sun, H., Tam, P. K.-H., Chiu, J.-F., Che, C.-M. (2007) Silver nanoparticles: partial oxidation and antibacterial activities. Journal of Biological Inorganic Chemistry $12(4), 527-534$.

5. Du, H., Lo, T.-M., Sitompul, J., Chang, M. W. (2012) Systems-level analysis of Escherichia coli response to silver nanoparticles: the roles of anaerobic respiration in microbial resistance. Biochemical and Biophysical Research Communications 424 (4), 657-662.

6. Seralathan, J., Stevenson, P., Subramaniam, S., Raghavan, R., Pemaiah, B., Sivasubramanian, A., Veerappan, A. (2014) Spectroscopy investigation on chemo-catalytic, free radical scavenging and bactericidal properties of biogenic silver nanoparticles synthesized using Salicornia brachiata aqueous extract. Spectrochimica Acta Part A: Molecular and Biomolecular Spectroscopy 118, 349355.

7. Seifipour, R., Nozari, M., Pishkar, L. (2020) Green synthesis of silver nanoparticles using Tragopogon collinus leaf extract and study of their antibacterial effects. Journal of Inorganic and Organometallic Polymers and Materials, 1-11.

8. He, Y., Wei, F., Ma, Z., Zhang, H., Yang, Q., Yao, B., Huang, Z., Li, J., Zeng, C., Zhang, Q. (2017) Green synthesis of silver nanoparticles using seed extract of Alpinia katsumadai, and their antioxidant, cytotoxicity, and antibacterial activities. RSC Advances 7 (63), 39842-39851.

9. Ghojavand, S., Madani, M., Karimi, J. (2020) Green synthesis, characterization and antifungal activity of silver nanoparticles using stems and flowers of felty germander. Journal of Inorganic and Organometallic Polymers and Materials, 1-11.

10. Renuka, R., Devi, K. R., Sivakami, M., Thilagavathi, T., Uthrakumar, R., Kaviyarasu, K. (2020) Biosynthesis of silver nanoparticles using phyllanthus emblica fruit extract for antimicrobial application. Biocatalysis and Agricultural Biotechnology, 101567.

11. Rodrigues, M. C., Rolim, W. R., Viana, M. M., Souza, T. R., Gonçalves, F., Tanaka, C. J., Bueno-Silva, B., Seabra, A. B. (2020) Biogenic synthesis and antimicrobial activity of silica-coated silver nanoparticles for esthetic dental applications. Journal of Dentistry, 103327.

12. Zou, Z., Xi, W., Hu, Y., Nie, C., Zhou, Z. (2016) Antioxidant activity of Citrus fruits. Food Chemistry 196, 885-896.

13. Yu, J., Xu, D., Guan, H. N., Wang, C., Huang, L. K. (2016) Facile one-step green synthesis of gold nanoparticles using Citrus maxima aqueous extracts and its catalytic activity. Materials Letters 166, 
110-112.

14. Rastogi, L., Arunachalam, J. (2013) Green synthesis route for the size controlled synthesis of biocompatible gold nanoparticles using aqueous extract of garlic (Allium sativum). Advanced Materials Letters 4, 548-555.

15. Madhusudhan, A., Reddy, G. B., Venkatesham, M., Veerabhadram, G., Kumar, D. A., Natarajan, S., Yang, M.-Y., Hu, A., Singh, S. S. (2014) Efficient pH dependent drug delivery to target cancer cells by gold nanoparticles capped with carboxymethyl chitosan. International Journal of Molecular Sciences 15 (5), 8216-8234.

16. Zhang, Y., Wang, L., Tian, J., Li, H., Luo, Y., Sun, X. (2011) Ag@Poly(m-phenylenediamine) core-shell nanoparticles for highly selective, multiplex mucleic acid detection. Langmuir 27 (6), 2170-2175.

17. Nakkala, J. R., Mata, R., Gupta, A. K., Sadras, S. R. (2014) Biological activities of green silver nanoparticles synthesized with Acorous calamus rhizome extract. European Journal of Medicinal Chemistry 85, 784-794.

18. Nabikhan, A., Kandasamy, K., Raj, A., Alikunhi, N. M. (2010) Synthesis of antimicrobial silver nanoparticles by callus and leaf extracts from saltmarsh plant, Sesuvium portulacastrum L. Colloids and Surfaces B: Biointerfaces 79 (2), 488-493.

19. Sadeghi, B., Rostami, A., Momeni, S. (2015) Facile green synthesis of silver nanoparticles using seed aqueous extract of Pistacia atlantica and its antibacterial activity. Spectrochimica Acta Part A: Molecular and Biomolecular Spectroscopy 134, 326-332.

20. Krishnaraj, C., Jagan, E., Rajasekar, S., Selvakumar, P., Kalaichelvan, P., Mohan, N. (2010) Synthesis of silver nanoparticles using Acalypha indica leaf extracts and its antibacterial activity against water borne pathogens. Colloids and Surfaces B: Biointerfaces 76 (1), 50-56.

21. Kaviya, S., Santhanalakshmi, J., Viswanathan, B., Muthumary, J., Srinivasan, K. (2011) Biosynthesis of silver nanoparticles using Citrus sinensis peel extract and its antibacterial activity. Spectrochimica Acta Part A: Molecular and Biomolecular Spectroscopy 79 (3), 594-598.

22. Gnanajobitha, G., Paulkumar, K., Vanaja, M., Rajeshkumar, S., Malarkodi, C., Annadurai, G., Kannan, C. (2013) Fruit-mediated synthesis of silver nanoparticles using Vitis vinifera and evaluation of their antimicrobial efficacy. Journal of Nanostructure in Chemistry 3 (1), 67.

23. Rajakumar, G., Rahuman, A. A. (2011) Larvicidal activity of synthesized silver nanoparticles using Eclipta prostrata leaf extract against filariasis and malaria vectors. Acta tropica 118 (3), 196-203.

24. Rout, A., Jena, P. K., Parida, U. K., Bindhani, B. K. (2013) Green synthesis of silver nanoparticles using leaves extract of Centella asiatica $L$. for studies against human pathogens. International Journal of Pharmacy and Biological Sciences 4 (4), 661-674.

25. Jain, D., Daima, H. K., Kachhwaha, S., Kothari, S. (2009) Synthesis of plant-mediated silver nanoparticles using papaya fruit extract and evaluation of their anti microbial activities. Digest Journal of Nanomaterials and Biostructures 4 (3), 557-563.

26. Santhoshkumar, T., Rahuman, A. A., Rajakumar, G., Marimuthu, S., Bagavan, A., Jayaseelan, C., Zahir, A. A., Elango, G., Kamaraj, C. (2011) Synthesis of silver nanoparticles using Nelumbo nucifera leaf 
extract and its larvicidal activity against malaria and filariasis vectors. Parasitology Research 108 (3), 693-702.

\section{Figures}

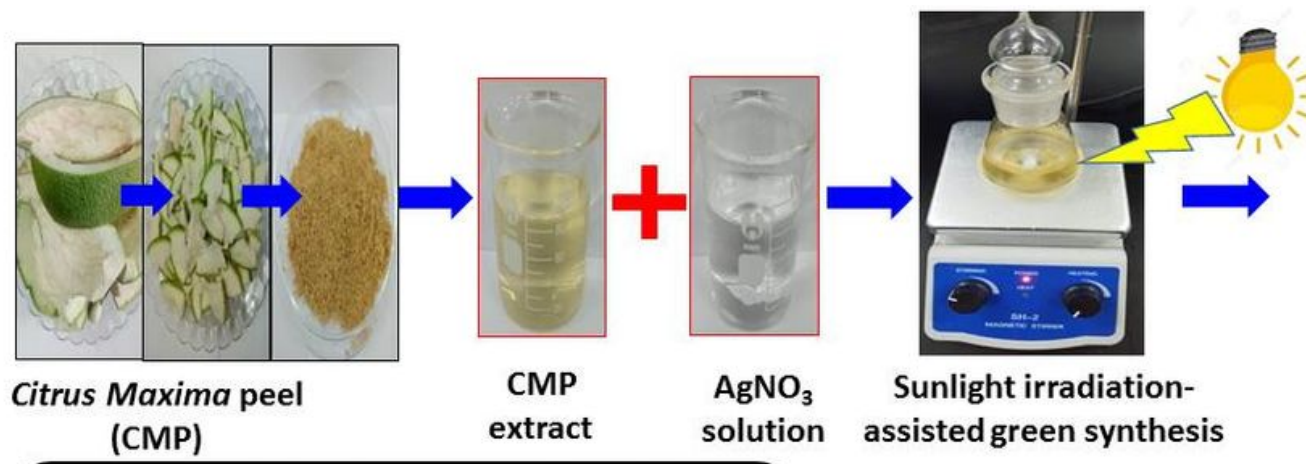

Effects of $\mathrm{Ag}^{+}$concentration, $\mathrm{Ag}^{+} / \mathrm{CMP}$ extract, synthesis duration

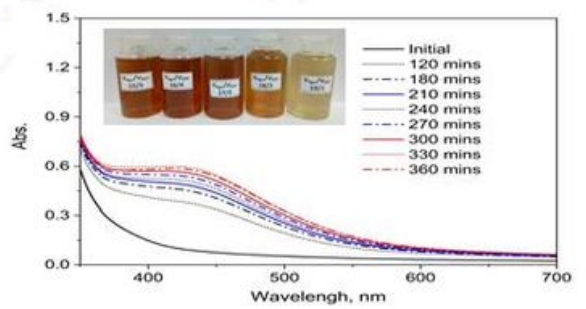

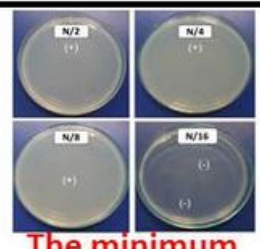

The minimum

batericidal concentration

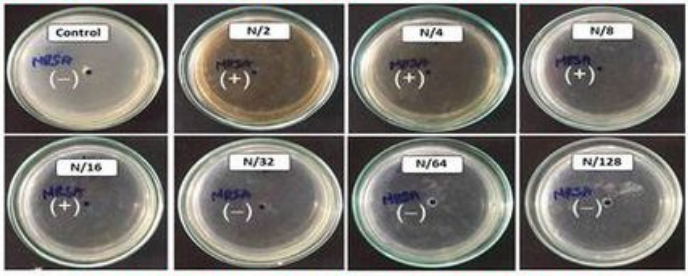

The minimum inhibitory concentration

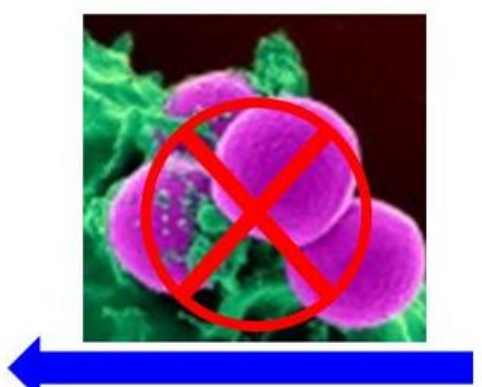

Antibacterial: Methicillin-resistant Staphylococcus aureus.

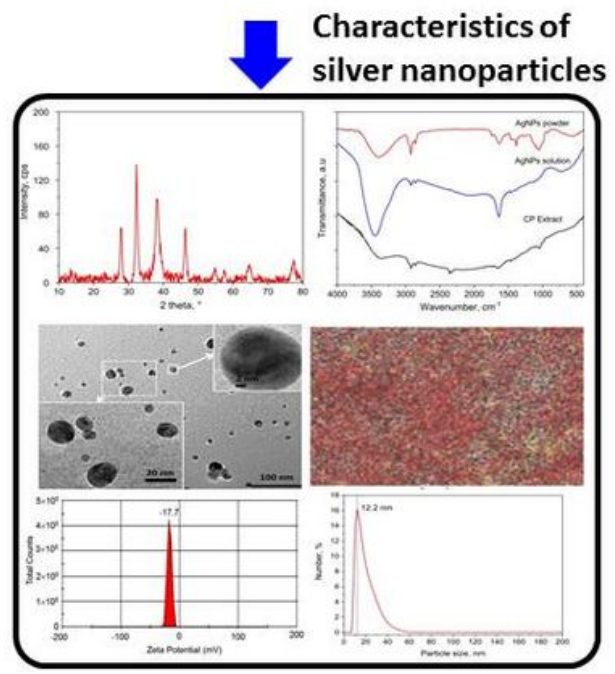

Figure 1

Schematic illustration of the experimental process.

\section{Supplementary Files}

This is a list of supplementary files associated with this preprint. Click to download.

- JIOPM2021Ag.MRSASupplementaryfile20.01.docx 